\title{
The development and pilot testing of a new instrument "Promoting Active Ageing in Older People with Mental Disorders Scale"
}

\author{
Kedsaraporn Kenbubpha, Isabel Higgins, Amanda Wilson, Sally Wai-Chi Chan \\ Faculty of Health and Medicine, School of Nursing and Midwifery, The University of Newcastle, Australia
}

Received: July 8, 2018

DOI: $10.5430 / \mathrm{cns} . \mathrm{v} 7 \mathrm{n} 2 \mathrm{p} 1$
Accepted: September 19, $2018 \quad$ Online Published: September 25, 2018

URL: https://doi.org/10.5430/cns.v7n2p1

\begin{abstract}
Background: There is little evidence about the factors that influence the promotion of active ageing, and the level of activity, in older people with mental disorders living in rural areas in Thailand.

Objective: The purpose of this study was to develop and test a new instrument: Promoting Active Ageing in Older People with Mental Disorders (PAA-MD).

Methods: The study involved item generation, content validity testing, face validity testing in 15 participants, and pilot testing in 40 participants of the PAA-MD. Content validity was evaluated using relevance ratings from an expert panel to calculate the content validity index for individual items (I-CVI) and the content validity index for the overall survey (S-CVI). Internal reliability was tested using Cronbach's alpha coefficient. External reliability was examined using Spearman's rank correlation coefficient. Results: The PAA-MD uses a self-rating scale for primary care providers and consists of 59 items in three sections. Section I, 14 items, evaluates characteristics of participants and familiarity of active ageing and related concepts. Section II, 22 items, examines the promotion of active ageing amongst older people with mental disorders. Section III, 23 items, measures factors that influence the promotion of active ageing. A five-point Likert scale is used in sections II and III. S-CVI of section II and III were 0.82 and 0.84. Five items in section II and three items in section III were deleted (I-CVI < 0.78). Cronbach's Alpha of section II and III was 0.975 and 0.964. The Spearman's Correlation in section II and III was 0.970 and 0.988 .

Conclusions: The PAA-MD takes 10-15 minutes to complete, has good content validity, high internal reliability, and a strong correlation of external reliability.
\end{abstract}

Key Words: Promoting active ageing, Mental disorders, Scale development

\section{INTRODUCTION}

Over the next 50 years, the number of over the age of 60 will increase from 600 million to 2 billion. ${ }^{[1]}$ The populations in many developing countries are ageing substantially faster than in developed countries. ${ }^{[2]}$ In developing countries, the ageing populations challenge national policies and infrastructures, particularly the health service systems. ${ }^{[3]}$
Older people are more likely to be the high risk of experiencing many factors including, poverty, social isolation, loss of independence, and loneliness, as well as physical conditions that influence emotional well-being, resulting in poorer mental health than the general population. ${ }^{[4]}$ Mental disorders in older people living in the community are common, ranging from $8.54 \%$ to $33 \% .^{[5-7]}$

\footnotetext{
*Correspondence: Kedsaraporn Kenbubpha; Email: kkenbubpha@yahoo.com; Address: Research and Training Center, Prasrimahabhodi Psychiatric Hospital, 212 Jangsanit Rd., Muang district, Ubon Ratchathani province, 34000, Thailand.
} 
Primary care centres can positively influence the health of older people living in communities worldwide. ${ }^{[8]}$ In developing countries, they are the front line of health services in caring for older persons, as the majority of older people live in the community. ${ }^{[9]}$ However, most primary care units are busy, and doctors, nurses and other healthcare providers lack time and resources to address all the needs of people in their care. ${ }^{[9,10]}$ Many primary care providers also lack the skills needed to care and support older people living in communities, particularly those with mental illnesses. ${ }^{[9,11]}$ As a result, older people with mental illness presenting to primary care settings are often not diagnosed and often go untreated. ${ }^{[1,12-15]}$

The aim of this study was to develop and test preliminary results of a new survey instrument: the "Promoting Active Ageing in Older People with Mental Disorders Scale" (PAAMD).

\section{MethodS}

The overall study used a mixed methods exploratory sequential design ${ }^{[16]}$ comprising two phases. Phase one involved a qualitative exploration of the promotion of active ageing in older people with mental disorders living in a Thai community. Focus group interviews with 14 primary care providers, including registered nurses, public health officers, public health administrators, dental assistant, aides, and workers working in Thai primary care units, were conducted to explore active ageing activities used at the time of the study. Participants had 12 years $(S D=8.91$, range 3-30) of experience in the primary care units and were predominantly female aged 24-52 years (mean $=37.07, S D=9.32$ ). This paper reports phase two of this study which involved the development of the PAA-MD and its pilot testing. Testing the psychometric properties of the PAA-MD, a cross-sectional study, is described elsewhere (paper in development).

\subsection{Item generation}

Item generation is the first step in developing of PAA-MD. It was developed in the Thai language using the findings from phase one of the study. These findings indicated three main themes: unfamiliarity with the concept of active ageing, promoting active ageing in communities, and factors influencing the promotion of active ageing. A recent study about the promotion of active ageing in Taiwan ${ }^{[17]}$ was also used in the development of the PAA-MD. Previous Thai studies were also used to generate the item pool for the instrument. ${ }^{[18-21]}$ The WHO active ageing model also guided the development of the PAA-MD. ${ }^{[2]}$ Two practitioner nurses who were key informants from the primary care units in the phase one of the focus group interviews were asked to review items in the PAA-MD to check the credibility of the findings from the FG qualitative study and to ensure internal consistency of the content. ${ }^{[23]}$ A five-point Likert scale ${ }^{[24]}$ was used to rate the score in each item of the PAA-MD. The Likert scale can be used to analyse parametric statistics from the study results in many ways. ${ }^{[25]}$ This type of scale is suitable for the PAA-MD because this instrument measures opinions of primary care providers about the promotion of active ageing.

\subsection{Content validity testing}

Content validity commonly depends on expert opinion because statistics cannot be used to determine how much a measure adequately covers a content topic or represents a construct. ${ }^{[26]}$ Waltz, Strickland, and Lenz ${ }^{[27]}$ recommend a panel of specialists to calculate agreement of item relevance with a minimum of three to a maximum of ten experts required. ${ }^{[28]}$ The PAA-MD was sent to a panel of nine experts specialising in multidisciplinary areas relevant to the study, namely, psychiatric nurses, psychiatrists, a community nurse, a gerontological nurse, a geriatrician, an expert in linguistics and culture, and an expert in instrument development in ageing. The experts were selected from the website of institutes in Thailand using purposive sampling. Experts were asked to rate their agreement regarding the relevance of each survey item on a 4-point scale where: $1=$ not relevant; $2=$ somewhat relevant; $3=$ quite relevant; to $4=$ very relevant. $^{[29]}$ Relevance ratings were used to calculate the content validity index for individual items (I-CVI) and the content validity index for the overall survey (S-CVI). I-CVI was calculated by the number of experts who rated either 3 or 4 for each item, divided by the number of experts.

According to Lynn's criteria, ${ }^{[28]}$ Polit and Beck, ${ }^{[29]}$ the values of I-CVI should be at least 0.78 when six to ten experts are used, and a value of S-CVI that is 0.80 or higher is considered acceptable. Items which did not reach minimum agreement were deleted or revised. The panel was asked to assess the clarity and conciseness of the close-ended items in the initial of PAA-MD with a "yes" or "no" response to each item. They were invited to make recommendations around the wording in any items thought to be ambiguous, unclear, or inappropriate.

\subsection{Face validity}

Face validity is a complex multidimensional construct which is used to evaluate how the items of instrument appear for respondents and others. ${ }^{[30]}$ To test face validity, the PAAMD was used with ten primary care providers working in the primary care unit in Ubon Ratchathani Province, Ban Dam Pra Health Promoting Hospital. They were selected by convenience sampling and asked to provide their opinion, 
suggestions, and feedback about the PAA-MD. The PAAMD has also examined face validity in five older people with mental disorders, including anxiety disorder or depressive disorder, who were otherwise stable health-wise and had good cognition. They were invited to comment on any item that was difficult to understand and to suggest activities around promoting active ageing in their community.

\subsection{Pilot study}

The purpose of a pilot study is to assess feasibility, adequacy of instrumentation, proposed methods and identify issues with data collection. The PAA-MD was distributed to a convenience sample of $40^{[31]}$ primary care providers in Muang, Khemmarat and Warinchamrap Districts, Ubon Ratchathani Province, Thailand.

The PAA-MD was tested for both internal and external reliability with the pilot study to ensure internal consistency reliability, and stability over time. It was tested to examine internal consistency reliability utilising Cronbach's alpha coefficient. Sufficient internal consistency reliability for a new instrument should indicate the Cronbach's alpha value of 0.70 and above, a range of inter-item correlations between 0.30 to 0.70 and a minimum corrected item-total correlation coefficient as $0.30 .^{[32,33]}$ These criteria were used to examine internal consistency reliability for retaining the items in this study.

External reliability, or test-retest reliability, within a 2-week interval in the same group of pilot participants, was tested to evaluate the stability over the time of the PAA-MD. Spearman's rank correlation coefficient was used to analyse the correlation between the mean score of the PAA-MD during test-retest reliability because of the small sample size. ${ }^{[34]}$ The acceptable external reliability is 0.7 and above. ${ }^{[24]}$

\subsection{Ethical considerations}

This study was approved by the Human Research Ethics Committee of the University of Newcastle, Approval No. H-2015-0379. The Ubon Ratchathani Provincial Health Officer, who heads all primary care units in Ubon Ratchathani Province, reviewed and approved the study. The Provincial Chief Medical Officer Ubon Ratchathani, Thailand provided final approval for the study.

\section{Results}

\subsection{Item generation}

The PAA-MD comprises three sections. Section I includes general information and familiarity with the concept of active ageing, and consists of 14 items and uses YES/NO responses. It was analyzed by frequency and percentage. Section II has activities promoted or offered to older people with mental

Published by Sciedu Press disorders living in the community and comprises 22 items. The summative scale, the Likert scale with five scale points, was used to the question "How often do you promote or offer the following activities of promoting active ageing in older people with mental disorders living in the community?" The five responses of the Likert scale ranged from $0=$ Never; 1 = Sometime; 2 = Often; 3 = Usually; 4 = Always. Section III contains factors that influence the promotion of active ageing in older people with mental disorders living in the community and has 23 items. The summative scale was used to assess the following, "You will be invited to give an opinion in each sentence for identifying factors that influence the promotion of active ageing in older people with mental disorders". The five responses of the Likert scale ranged from strongly disagree to strongly agree $(1=$ strongly disagree, 2 = disagree, $3=$ moderately agree, $4=$ agree, and $5=$ strongly agree). Only section II and III were examined to find out the psychometric properties from the pilot testing.

\subsection{Content validity}

Seven experts, two psychiatric nurses, two psychiatrists, a community nurse, a geriatrician, and an instrument developer, responded to the initial survey instrument. The content validity index (S-CVI) of section II of PAA-MD was 0.82 . There were five items, namely, 1, 2, 3, 5, 19 where the validity index (I-CVI) fell below 0.78 . They were reviewed and revised. The S-CVI of section III of PAA-MD was 0.84 . There were three items, namely, 2, 6, 11 in the I-CVI that were below 0.78 .

The PAA-MD was revised in 28 items which divided into 52 sub-items to measure promotion activities of active ageing in older people with mental disorder living in the community. There were 38 items which identify factors that influence the promotion of active ageing in older people with mental disorders living in the community. The PAA-MD was returned to the expert panel for final review prior to distribution for testing face validity.

\subsection{Face validity}

Face validity testing involved ten female primary care providers; registered nurses, assistant health officers, and assistant dentists, aged 31-58 years. Nine primary care providers had graduated with a bachelor degree. Five older people (females $=4$, male $=1$ ) with stable symptoms of anxiety and depression, aged 62-73 years, also participated in face validity testing.

Participants indicated that most of the items of the PAA-MD were easy to understand, and only minor rewording was suggested. It was noted that some words were redundant, and some questions were too long. It was also recommended that 
examples of promotion of active ageing from their communities were added into the PAA-MD.

\subsection{The pilot study}

The majority of participants in the pilot study were female, with ages ranging from 22-60 years and a mean age of 34.88 years $(S D=9.32)$. They consisted of registered nurses, assistant pharmacists, and health officers. Most (75\%) had bachelor degrees, and $67.5 \%$ worked in Health Promoting Hospitals.

The results of the internal reliability testing of section II of the PAA-MD showed a total Cronbach's Alpha of 0.975. Items 1.2, 1.3, and 21.2 had a corrected item-total correlation coefficient lower than 0.30 (see Table 1). These were removed from the PAA-MD. The internal reliability in Section III of the PAA-MD presented a total Cronbach's Alpha of 0.964 for item 14 indicating the corrected item-total correlation coefficient lower than 0.30. Then, it was deleted from the draft of PAA-MD (see Table 2).

Table 1. Internal reliability $(\mathrm{n}=40)$ and external reliability $(n=32)$ of section II in the PAA-MD

\begin{tabular}{llll}
\hline Scale & $\begin{array}{l}\text { Number of } \\
\text { items }\end{array}$ & $\begin{array}{l}\text { Cronbach's } \\
\text { Alpha }\end{array}$ & $\boldsymbol{r}$ \\
\hline Participation & 18 & 0.923 & $0.978^{*}$ \\
Education & 6 & 0.842 & $0.983^{*}$ \\
Health & 19 & 0.982 & $0.988^{*}$ \\
Leisure & 7 & 0.761 & $0.951^{*}$ \\
Security & 6 & 0.827 & $0.939^{*}$ \\
Total & 56 & 0.975 & $0.970^{*}$ \\
\hline
\end{tabular}

Note. ${ }^{*} p<.01$, two-tailed

Table 2. Internal reliability $(n=40)$ and external reliability $(\mathrm{n}=32)$ of section III in the PAA-MD

\begin{tabular}{llll}
\hline Scale & $\begin{array}{l}\text { Number of } \\
\text { items }\end{array}$ & $\begin{array}{l}\text { Cronbach's } \\
\text { Alpha }\end{array}$ & $\boldsymbol{r}$ \\
\hline Participation & 18 & 0.923 & $0.978^{*}$ \\
Education & 6 & 0.842 & $0.983^{*}$ \\
Health & 19 & 0.982 & $0.988^{*}$ \\
Leisure & 7 & 0.761 & $0.951^{*}$ \\
Security & 6 & 0.827 & $0.939^{*}$ \\
Total & 56 & 0.975 & $0.970^{*}$ \\
\hline
\end{tabular}

Note. ${ }^{*} p<.01$, two-tailed

The test-retest reliability of the PAA-MD, it was recirculated to all forty participants after a two-week period of the first round in the process of pilot testing. Thirty-two participants (80\%) completed the draft of PAA-MD on both occasions. The results of test-retest reliability indicate that section II of the PAA-MD measuring the promotion of active ageing in older people with mental health disorders living in the community was significantly correlated with a total score. Each factor: participation, education, health, leisure, and security accounted for $0.970,0.978,0.983,0.988,0.951$, and 0.939 respectively ( $p$-value $<.01$ ) as shown in Table 1 .

Section III of the PAA-MD, identifying factors that influence the promotion of active ageing in older people with mental disorders living in the community, showed significant correlation between the total score and each factor: facilitators, barriers, knowledge, skills, and resources and support accounted for $0.988,0.990,0.966,0.972,0.961$, and 0.983 respectively ( $p$-value $<.01$ ) as presented in Table 2 .

The number of items in Section II of the PAA-MD which measured the promotion of active ageing in older people with mental disorders living in the community consisted of 56 items before pilot study testing. Three items were removed due to the corrected item-total correlation coefficient is lower than 0.30 . Two new items were included from suggestions made by the pilot participants. Therefore, there were 55 items whose psychometric properties were tested in the next phase.

There were initially 38 items in Section III of the PAA-MD, for identifying factors that influence the promotion of active ageing in older people with mental disorders. However, one item was removed as the corrected item-total correlation coefficient was lower than 0.30 .

\section{Discussion}

The objective of this study was to develop and test the preliminary results of the PAA-MD in terms of item generation, content validity, face validity, and the pilot study to examine the internal and external reliability. Previous instruments in relation to the concept of active ageing in older people with mental disorders are under-researched have still less evidence and they are not examined to find out psychometric properties. ${ }^{[35]}$ The PAA-MD was developed by using components of the WHO active ageing model, ${ }^{[22]}$ namely, health, participation, and security. Moreover, it was created by using some components of a previous study in from Taiwan, which was developed to examine activities of active ageing in general older people but it was not validated to test psychometric properties. ${ }^{[17]}$ The components of education and leisure of general older people were used to develop the PAA-MD following the previous study. ${ }^{[17]}$

In addition, the factors that influence the promotion of active ageing in older people with mental disorders in section III of the PAA-MD used some components from the findings of a previous qualitative study that explored community nurses' perspectives of facilitators and barriers in working 
for health promotion, such as knowledge of health providers, guidelines, resources and support. ${ }^{[36]}$ It is also created by exploring the Thai culture and the health care system in Thailand by using the findings of a qualitative study from focus groups interviews with primary care providers. The PAA-MD was developed and tested psychometrically using a mixed methods design which provides a rigorous way for developing and testing a new instrument. ${ }^{[16]}$ This should result in the PAA-MD being able to assess and monitor the frequency, range of activities and factors associated with active ageing in older people with mental disorders.

Content validity testing of PAA-MD from an expert panel indicated that there were five items in section II and three items in section III of the PAA-MD that were less than 0.78 of item relevance from the expert's opinion. They were then revised and reviewed because the content validity index should be at least 0.78 when six to ten experts are asked to rate the relevance of the item in a new instrument. ${ }^{[28]}$

The pilot testing showed that the overall internal consistency reliability in section II of the PAA-MD was excellent in terms of acceptability $(\alpha>0.90)$ which indicates an acceptable level of the Cronbach's alpha coefficient of more than the 0.70 recommended by George and Mallery. ${ }^{[37]}$ The internal consistency reliability in dimensions of participation and health were at an excellent level $(\alpha>0.90)$, dimensions of education and security were a good level ( $\alpha>0.80$ to $0.90)$, and leisure was at an acceptable level $(\alpha>0.70)$. The results imply that section II in the PAA-MD has sufficient internal consistency reliability. Nevertheless, the findings from each item of section II in the PAA-MD found three items whose corrected item-total correlation was less than the acceptable level of less than 0.3 as recommended by Nunnally and Bernstein ${ }^{[32]}$ and Ferketich. ${ }^{[33]}$ Two of the three items were about the religious activities of Christians and Muslims. The majority of Thai older people are Buddhist and religious beliefs impact on their life, particularly for those who live in communities. ${ }^{[38]}$ The third item was recreation activities in the community with the local drama that was similar to local dancing in the same main-item. They were therefore removed from this part of the PAA-MD. The external reliability, or stability over time, used Spearman's rank correlation calculating the mean difference in scores between the first and second pilot testing. ${ }^{[39]}$ The results from the thirty-two participants of test-retest reliability of both the overall items of section II and each component, namely, participation, education, health, leisure, and security, indicated a strong correlation with a coefficient value between 0.8 to $1{ }^{[39]}$ These findings imply that section II of the PAA-MD is stable over time or external reliability is strong.
The internal consistency reliability of section III indicated that the overall items and each component, namely, facilitators, understanding, skills, and resources and support were at an excellent level of acceptability $(\alpha>0.90)$. The component of barriers or obstacles was at a good level $(\alpha>$ $0.80){ }^{[37]}$ Therefore, this section of the PAA-MD is deemed to be at an acceptable level of internal reliability. ${ }^{[37]}$ Only one item, "some belief of health behaviour in older people in our communities is not appropriate", showed that the corrected item-total correlation was at a less than acceptable level, using criteria definition from Ferketich, ${ }^{[33]}$ and Nunnally and Bernstein. ${ }^{[32]}$ It was removed from section III of the PAA-MD. The external reliability, or stability over time, from thirty-two participants in section III of the PAA-MD, indicated strong correlation both of the overall section and each factor, namely facilitators, barriers or obstacles, understanding, skills, resources and support. These results indicate this section of the PAA-MD is stable over time.

\section{Strengths and limitations}

The strengths of this research are the development of the PAA-MD used many sources such as focus groups interviews and the WHO's concept of active ageing as well as previous studies. The content validity has tested a variety of experts and face validity was examined using primary care providers and older people with mental disorders. Both internal and external reliability were evaluated. These strengths are quite a high standard and relevant as recommended by Creswell and Clark, ${ }^{[16]}$ and DeVellis. ${ }^{[24]}$

However, this study has some limitations. The PAA-MD cannot be represented as the national instrument because it was developed and tested by a convenience sampling in primary care units of 2 provinces from 76 provinces of Thailand. In face validity evaluation, only a registered nurse who was the key informant from that setting was available to meet with the researcher to hear the information. The other nine primary care staff provided written feedback about the wording of the items, and the researcher picked these PAA-MD up later. The pilot study to assess test-retest reliability analysed the data from 32 participants of the 40 who had initially completed the PAA-MD in the first round. However, the number of participants was still higher than the recommended sample size for a pilot study which is from ten to forty per group as per Hertzog. [31]

\section{Conclusions}

The PAA-MD was developed in the Thai language using findings from the descriptive qualitative study, previous studies, and the concept of active ageing from WHO. The preliminary results of the PAA-MD; the promotion of active ageing in 
older people with mental disorders living in communities, and identification of factors that influence the promotion of active ageing in this group indicated that it has good content validity after some items were removed because individual content validity index was lower than an acceptable level. The face validity was well accepted by both primary care providers and older people with mental disorders. The PAAMD has high internal consistency reliability. The test-retest reliability showed the PAA-MD was satisfactory with a significantly strong relationship compared with the response from the first and second times of the participants in pilot testing which could be interpreted as the PAA-MD being stable over time. The PAA-MD contains 78 items divided into three sections as reported in the previous section. This instrument is intended to be used to assess how primary care providers promote active ageing in older people, aged 60 years and older, who are experiencing anxiety, depression disorders or similar issues in Thailand.
However, the PAA-MD should be tested the psychometric properties using a large sample size to analyse the instrument with regards exploratory factor analysis and Cronbach's Alpha coefficient. This is because it is quite a new survey instrument in this subject area.

\section{ACKNOWLEDGements}

The Australian Government Research Training Program Scholarship provided a PhD study scholarship for Kedsaraporn Kenbubpha. Yasothon Health Provincial Offices for permission to collect data in their primary care units. All participants for their valuable time and shared experience as well as good cooperation. Especially thank you to Dr Christopher Oldmeadow, a statistician from the Hunter Medical Research Institution in Australia for consulting and confirming the process of data analysis.

\section{Conflicts of Interest Disclosure}

The authors declare they have no conflicts of interest.

\section{REFERENCES}

[1] World Health Organization. Mental health and older adults. 2013 [cited 2014 August 20]. Available from: http://www . who . int/me diacentre/factsheets/fs381/en/

[2] United Nations, Department of Economic and Social Affairs, and Population Division. World population ageing 2015, P.D. Department of Economic and Social Affairs, Editor. UN: New York; 2015.

[3] World Health Organization. Global health and aging. 2011 [cited 2014 November 13]. Available from: http://www. who.int/agei ng/publications/global_health/en/

[4] World Federation for Mental Health. Mental health and older people. 2013 [cited 2017 January 17]. Available from: http://lmentala.net/admin/archivosboletin/WMHDay_ 2013_v3_small_file.pdf

[5] Ritchie K, Artero S, Beluche I, et al. Prevalence of DSM-IV psychiatric disorder in the French elderly population. The British Journal of Psychiatry. 2004; 184(2): 147-152. PMid: 14754827. https://doi.org/10.1192/bjp.184.2.147

[6] Gum AM, King-Kallimanis B, Kohn R. Prevalence of mood, anxiety, and substance-abuse disorders for older Americans in the national comorbidity survey-replication. The American Journal of Geriatric Psychiatry. 2009; 17(9): 769-781. PMid: 19700949. https: //doi.org/10.1097/JGP.0b013e3181ad4f5a

[7] Olafsdottir M, Marcusson J, Skoog I. Mental disorders among elderly people in primary care: The Linköping study. Acta Psychiatrica Scandinavica. 2001; 104(1): 12-18. PMid: 11437744. https : //doi.org/10.1034/j.1600-0447.2001.104001012.x

[8] World Health Organization. Older people and primary health care. 2015 [cited 2015 April 4]. Available from: http://www . who.int/ ageing/primary_health_care/en/

[9] World Health Organization. Towards age-friendly primary health care. 2004 [cited 2014 October 11]. Available from: http: //www . who.int/ageing/publications/phc/en/
[10] World Health Organization and Wonca Working Party on Mental Health. What is primary care mental health? Mental Health in Family Medicine. 2008; 5(1): 9-13. PMid: 22477841.

[11] Petersen I, Joshua S, Arvin B, et al. Lessons from case studies of integrating mental health into primary health care in South Africa and Uganda. International Journal of Mental Health Systems. 2011; 5(1): 1. PMid: 21496242. https://doi.org/10.1186/1752-4 458-5-8

[12] Richardson TM, He H, Podgorski C, et al. Screening depression aging services clients. The American Journal of Geriatric Psychiatry. 2010; 18(12): 1116-1123. PMid: 20808102. https ://doi .org/10 . 1097/JGP. 0b013e3181dd1c26

[13] Runciman P, Watson H, Mcintosh J, et al. Community nurses' health promotion work with older people. Journal of Advanced Nursing. 2006; 55(1): 46-57. PMid: 16768739. https://doi .org/10.111 $1 / \mathrm{j} .1365-2648.2006 .03882 . \mathrm{x}$

[14] Muir-Cochrane E, O'Kane D, Barkway P, et al. Service provision for older people with mental health problems in a rural area of Australia. Aging \& Mental Health. 2014; 18(6): 759-766. PMid: 24499436. https ://doi.org/10.1080/13607863.2013.878307

[15] Grundberg Å, Hansson A, Hillerås P, et al. District nurses' perspectives on detecting mental health problems and promoting mental health among community-dwelling seniors with multimorbidity. Journal of Clinical Nursing. 2016; 25(17-18): 2590-2599. PMid: 27273609. https://doi.org/10.1111/jocn. 13302

[16] Creswell JW, Clark VL. Designing and conducting mixed methods research. 2nd ed. San Francisco, CA: SAGE Publications; 2011.

[17] Lin WI, Chen ML, Cheng JC. The promotion of active aging in Taiwan. Ageing International. 2013;39(2): 81-96. https ://doi .org/ $10.1007 / \mathrm{s} 12126-013-9192-5$

[18] Thanakwang K, Isaramalai SA, Hattakit U. Thai cultural understandings of active ageing from the perspectives of older adults: A qualitative study. Pacific Rim International Journal of Nursing Research. 2014; 18(2): 152-165. 
[19] Chansarn S. Active ageing of elderly people and its determinants: Empirical evidence from Thailand. Asia-Pacific Social Science Review. 2012; 12(1).

[20] Nantsupawat W, Kamnuansilapa P, Sritanyarat W, et al. Family relationships, roles and the meaning of active aging among rural Northeastern Thai elders. Pacific Rim International Journal of Nursing Research. 2010; 14(2): 137-148.

[21] Thailand. Department of Mental Health. Guideline of psychosocial support for protecting mental health problems in older people (In Thai). Nonthaburi, Thailand: Department of Mental Health; 2015.

[22] World Health Organization. Active ageing: A policy framework. 2002 [cited 2014 August 12]. Available from: http: //www . who. in t/ageing/publications/active_ageing/en/

[23] Mastaglia B, Toye C, Kristjanson LJ. Ensuring content validity in instrument development: Challenges and innovative approaches. Contemporary Nurse. 2003; 14(3): 281-291. PMid: 12868667. https://doi.org/10.5172/conu.14.3.281

[24] DeVellis RF. Scale development: Theory and application. 2nd ed. San Francisco, CA: SAGE Publications; 2003. PMid: 14558062.

[25] Hartley J. Some thoughts on Likert-type scales. International Journal of Clinical and Health Psychology. 2014; 14(1): 83-86. https : //doi.org/10.1016/S1697-2600(14)70040-7

[26] Kimberlin CL, Winterstein AG. Validity and reliability of measurement instruments used in research. American Journal of HealthSystem Pharmacy. 2008; 65(23): 2276-84. PMid: 19020196. https : //doi.org/10.2146/ajhp070364

[27] Waltz CF, Strickland OL, Lenz ER. Measurement in nursing and health research. 3rd ed. New York, NY: Springer Publishing; 2005.

[28] Lynn MR. Determination and quantification of content validity. Nursing Research. 1986; 35(6): 382-386. PMid: 3640358. https : //doi.org/10.1097/00006199-198611000-00017

[29] Polit DF, Beck CT. The content validity index: Are you sure you know what's being reported? Critique and recommendations. Re- search in Nursing \& Health. 2006; 29(5): 489-497. PMid: 16977646. https : //doi.org/10.1002/nur. 20147

[30] Thomas SD, Hathaway DK, Arheart KL. Technical notes: Face validity. Western Journal of Nursing Research. 1992; 14(1): 109-112. PMid: 1546473. http://dx.doi.org/10.1186/1472-6963-1 $0-162$

[31] Hertzog MA. Considerations in determining sample size for pilot studies. Research in Nursing and Health. 2008; 31(2): 180-191. PMid: 18183564. https ://doi.org/10.1002/nur. 20247

[32] Nunnally J, Bernstein I. Psychometric theory. 3rd ed. New York, NY: McGraw-Hill; 1994.

[33] Ferketich S. Focus on psychometrics: Aspects of item analysis. Research in Nursing and Health. 1991; 14(2): 165-168. PMid: 2047538. https://doi.org/10.1002/nur.4770140211

[34] Cohen RJ, Swerdlik ME, Sturman ED. Psychological testing and assessment: An introduction to tests and measurement. 8th ed. New York, NY: McGraw-Hill; 2013.

[35] Hutchison T, Morrison P, Mikhailovich K. A review of the literature on active ageing. 2006 [cited 2014 November 4]. Available from: ht tp://www . canberra.edu.au/centres/research/healthp act/Active\%20Ageing_final\%20report\%20_edited_.pdf

[36] Wilhelmsson S, Lindberg M. Health promotion: Facilitators and barriers perceived by district nurses. International Journal of Nursing Practice. 2009; 15(3): 156-163. PMid: 19531073. https: //doi.org/10.1111/j.1440-172X.2009.01740.x

[37] George D, Mallery P. SPSS for Windows step by step: A simple guide and reference 9.0 update. 2nd ed. Boston, MA: Allyn \& Bacon; 2000.

[38] Knodel J, Prachuabmoh V, Chayovan N. The changing well-being of Thai elderly: An update from the 2011 survey of older persons in Thailand. 2013 [cited 2015 January 20]. Available from: https ://doi.org/10.1111/j.1440-172X.2009.01740.x

[39] Smarandache F. Alternatives to Pearson's and Spearman's correlation coefficients. Bulletin of Statistics \& Economics. 2008; 3(S09): 47-53. 